\title{
Test Results for a Bi-2223 HTS Racetrack Coil for Generator Applications
}

\author{
Lembit Salasoo, Kenneth G. Herd and E. Trifon Laskaris \\ GE Corporate Research \& Development Center, Schenectady, New York \\ Howard R. Hart Jr. and M.V.K. Chari
}

formerly GE Corporate Research \& Development Center, Schenectady, New York

\begin{abstract}
Testing, results and analysis of a Bi2223 model superconducting generator coil produced under the DOE Superconductivity Partnership Initiative are presented. The test arrangement enables coil energization with $d c$ and transient currents over a range of operating temperatures to explore coil performance under conditions analogous to those that would be experienced by a superconducting generator field coil. Analytic calculations of coil ac and ohmic losses and temperature rise compare well with experimental measurements. Good performance is predicted for a typical 3-phase fault condition. Coil steady state and transient performance can be predicted with confidence for full scale superconductor application.
\end{abstract}

\section{INTRODUCTION}

The design and construction of the Bi-2223 HTS racetrack model generator coil is described in a companion paper [1]. In a generator, the rotating field coil, cooled to its $20 \mathrm{~K}$ operating temperature, will be excited with direct current to magnetize the generator at a field current level that varies depending on the generator load. Under transient conditions such as faults, scheduled generator loading changes or transmission network switching, the field coil excitation will undergo a transient influenced by the generator electromagnetic (EM) shields, electrical grid parameters, generator and prime mover dynamic mechanical characteristics and the excitation control system dynamics. The most severe operational field current transients occur under sudden short circuit conditions. Lowlevel steady ac currents may also be introduced into the field circuit from non-ideal generator geometry, load unbalance or harmonics.

Many of the operational limits on a superconducting generator field coil current are related to thermal issues. Under steady-state conditions, the coil heat generation from electromagnetic effects must not drive the heat budget over the cryogenic refrigeration capability, and under transient conditions, local coil heat capacity and cryostat heat transfer characteristics must assure a return to a stable post-transient operating condition. One of the advantages of HTS materials operating in the $20 \mathrm{~K}$ regime is the roughly 1-1/2 order-of-magnitude higher heat capacity, compared to the typical 4K LTS operating temperature, which is expected to greatly benefit thermal transient stability. Coil heat generation is expected to include the flux flow regime losses, as described by, for instance, the " $"$ " value of the coil conductor, and superconductor wire ac

Manuscript received August 27, 1996.

This work was supported in part by the U.S. Department of Energy under Contract No. DE-FC02-93CH10589. losses of the usual hysteretic and eddy current types.

The model coil testing covered performance under dc and transient current conditions, to study the magnitude and nature of coil losses. Dc testing gave results for fluxflow losses alone, which could then be subtracted from transient current testing results to give the ac loss components.

A dc loss model was developed from test data for all conductor lengths used, the racetrack coil magnetic field profile and $\mathrm{Bi}-2223$ critical surface data. An anisotropic critical-state ac loss model was used. The adequacy of these models for design of superconducting generator coils is discussed and the performance under a typical field current transient is modeled.

\section{CHARACTERISTIC}

The coil was cooled to $77 \mathrm{~K}$ with liquid nitrogen and the static voltage-current characteristic was obtained from a four-wire measurement using increasing levels of direct current. Subsequently the coil was cooled to approximately $19 \mathrm{~K}$ with the refrigeration system and a second current-voltage characteristic was measured using the same procedure.

The $77 \mathrm{~K}$ voltage-current results in Fig. 1 exhibit 3 regimes. At currents between 4 and $11 \mathrm{~A}$ an $\mathrm{n}$ value of 5 is displayed, while at higher currents, the effect of stabilizer current sharing is seen. Below $4 \mathrm{~A}$, the voltage-current characteristic transitions to a residual resistivity regime with exponent in the 1.0-1.5 range. Two regimes can be discerned in the $19 \mathrm{~K}$ results: a 1.0-to-1.5-exponent residual resistivity regime below $20 \mathrm{~A}$, and an approximately $\mathrm{n}=5$ exponent between $25-40 \mathrm{~A}$.

Voltage-current characteristics for $9 \mathrm{Bi}-2223$ tape lengths produced by Intermagnetics General Corp. (IGC) in this program were examined (Fig. 2). The curves were obtained by IGC for $77 \mathrm{~K} \mathrm{I}_{c}$ value determination at selffield after conductor lamination and insulation. The characteristics show a 0.2-0.7 exponent at lower currents, transitioning to a value in the range 5-8 at higher currents. The transition is at electric fields in the range $30-300$ $\mu \mathrm{V} / \mathrm{m}(0.3-3 \mu \mathrm{V} / \mathrm{cm})$, and it is possible to express the relationships as the sum of two exponentials:

$$
E=a . J^{m}+b . J^{n}
$$

Such an equation is similar to the relationship determined for PIT Bi-2223/Ag tapes studied by a group at Brookhaven National Laboratory [2], [3]. Those studies indicate a conductor handling-dependent residual resistivity level, and exponent analogous to $\mathrm{m}$ in the 1.0-1.2 range.

A model of the racetrack coil was set up where the critical current at each point was determined by the local

$$
\text { FCO2-93CH } 10.589
$$




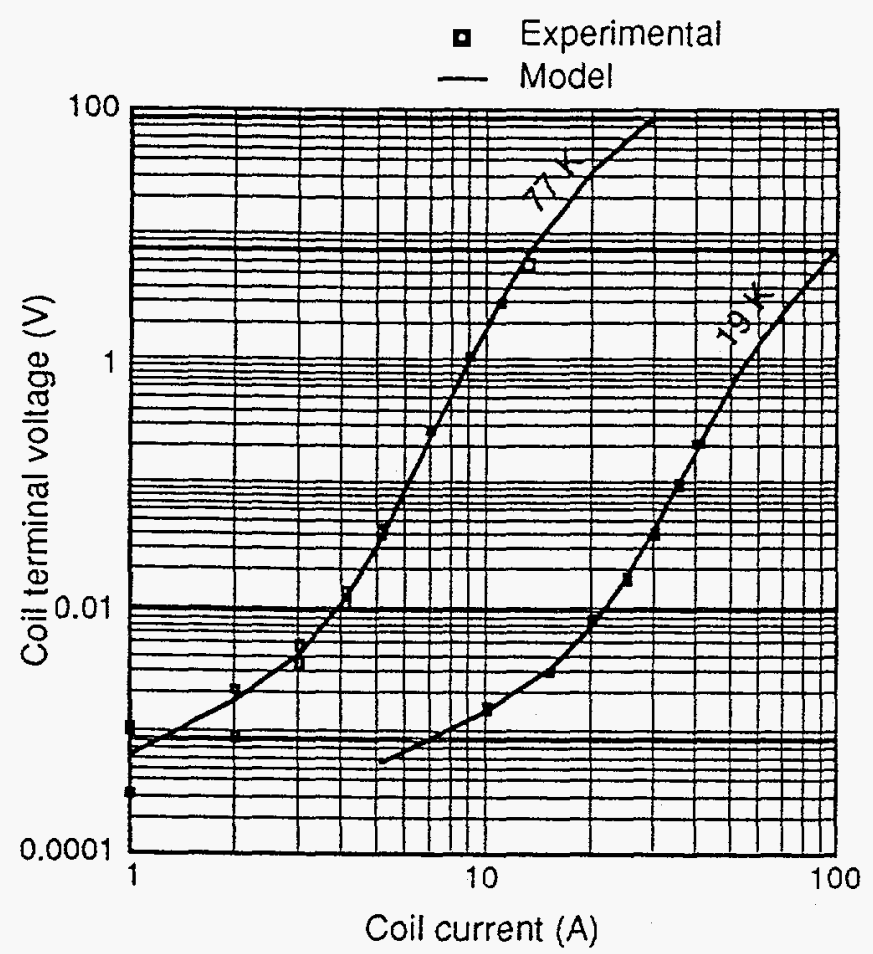

Fig. 1. Coil terminal characteristic.

magnetic field (normal to the tape width) and temperature, by scaling the critical current of the particular $j$-th tape length measured at self-field and $77 \mathrm{~K}, \mathrm{I}_{\mathrm{cj}}(0 \mathrm{~T}, 77 \mathrm{~K})$, according to the $\mathrm{Bi}-2223$ critical surface determined by Tkaczyk et al. [4] as follows:

$$
I_{c j}\left(B_{\perp}, T\right)=I_{c}(0 T, 77 K) \cdot \frac{J_{c}\left(B_{\perp}, T\right)}{J_{c}(0 T, 77 K)},
$$

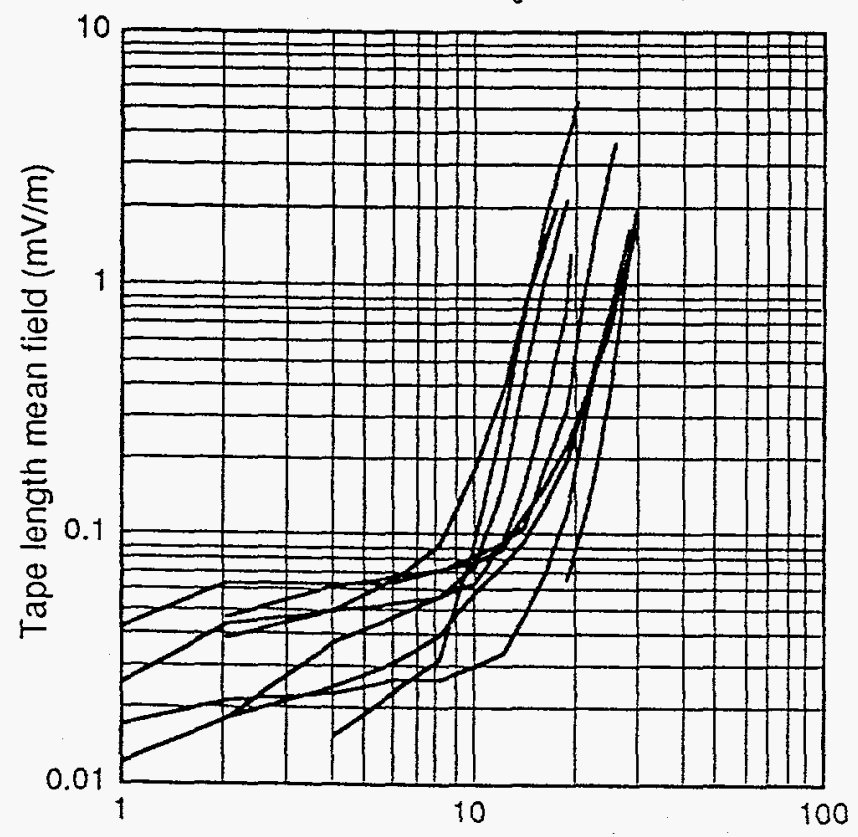

Tape length test current $(A)$

Fig. 2. Tape length characteristics before winding. where $J_{c}\left(B_{\perp}, T\right)$ is interpolated from the critical surface data. Common $\mathrm{m}$ and $\mathrm{n}$ exponents were used for all 23 tape lengths used in the coil, and the relative magnitudes of the $\mathrm{m}$-exponent and $\mathrm{n}$-exponent terms were assumed constant at every local $I_{c}$ :

$$
E_{j}(B, T)=E_{0}\left[k \cdot i^{m}+(1-k) \cdot i^{n}\right] .
$$

Here $E_{0}$ is the $0.1 \mathrm{mV} / \mathrm{m}$ reference field for $I_{c}$ determination, $\mathrm{k}$ is the relative contribution of the $\mathrm{m}$-exponent term to $E_{0}$ and $i$ is the dimensionless superconductor current:

$$
i=\frac{I}{I_{c}\left(B_{\perp}, T\right)}
$$

The local superconductor current is obtained by solving the current division between the superconductor and the ohmic resistance of the stabilizer. Therefore all the conductor lengths have common $\mathrm{k}, \mathrm{m}$ and $\mathrm{n}$ parameters, and $\mathrm{I}_{\mathrm{cj}}(0 \mathrm{~T}, 77 \mathrm{~K})$ is the only variable specific to the particular tape length. Good fits (shown in Fig. 1) were obtained for the $77 \mathrm{~K}$ and $19 \mathrm{~K}$ data using the parameters in Table I.

TABLE I

CONDUCTOR PARAMETERS FOR GOOD FT

\begin{tabular}{lll}
\hline Parameter & $19 \mathrm{~K}$ value & $77 \mathrm{~K}$ value \\
\hline $\mathrm{k}$ & 0.075 & 0.05 \\
$\mathrm{~m}$ & 1.2 & 1.2 \\
$\mathrm{n}$ & 5.0 & 5.0 \\
\hline
\end{tabular}

It is seen that the exponents for a good fit are the same for the two temperatures, while the appropriate $\mathrm{k}$ coefficient is $33 \%$ lower at $77 \mathrm{~K}$.

\section{AC CHARACTERISTIC}

In these $19 \mathrm{~K}$ tests using a 50A $300 \mathrm{~V}$ power supply, the power supply voltage limit was preset. The current setpoint was raised from zero to the test value and after the test interval returned to zero. The coil ramped up to the current setpoint, typically overshooting due to the power supply control circuit response, and ramped down by discharge through the power supply freewheeling diode or equivalent (typical test current transient in Fig. 3). Transient coil currents and system temperatures were recorded. The results, including the temperature excursion measured on the inside of the middle of the racetrack turn, $13 \mathrm{~mm}$ from the edge of the 10-cm-wide coil (Fig. 4), are summarized in Table II.

The transient tests were modeled by combining the measured dc terminal characteristic with an anisotropic critical-state model of hysteretic loss. Calculations indicated that eddy current losses and tape splice resistance losses are negligible. The hysteretic loss model was based on the fieid excursion normal to the tape width and critical surface based on magnetization measurements [4], which is 2 to 3 times higher than the surface from transport current measurements but otherwise of the same form. It is felt that the transport $J_{c}$ values are consistent with weak 


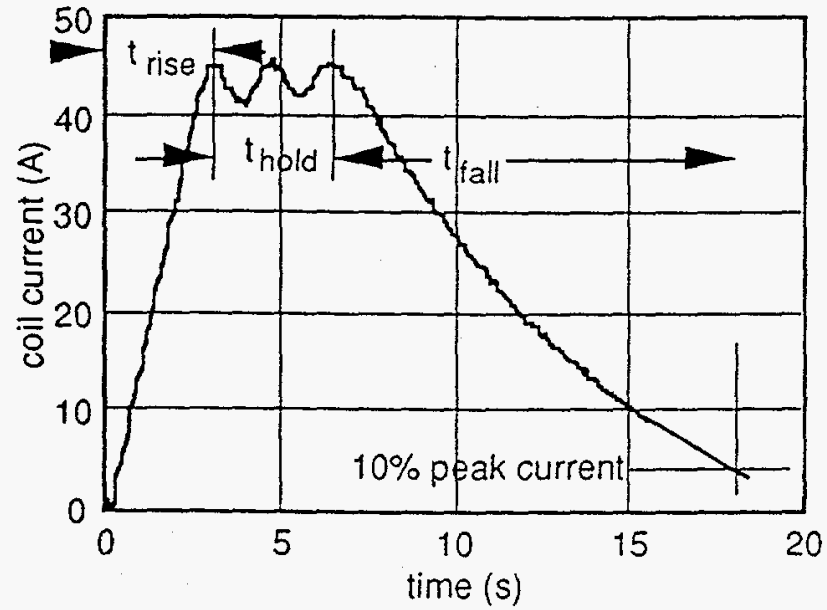

Fig. 3. Typical current transient for ac loss test.

links in the conductor that limit supercurrent between regions of higher $J_{c}$, which govern the magnetization-based $\mathrm{J}_{\mathrm{c}}$. Thus most of the $\mathrm{Bi}-2223$ volume exhibits the higher $\mathrm{J}_{\mathrm{C}}$ value, and that value dominates the total conductor hysteretic loss. The hysteresis model included the effect that at low values of normal $B$, the superconductor screening currents exclude field over much of the tape width, causing significant diamagnetism and field enhancement at the tape edge, while increased applied B penetrates the tape more, reducing the edge field enhancement.

The $19 \mathrm{~K}$ thermal diffusivities of the coil composite are approximately $0.02,3 \times 10^{-5}$ and $3 \times 10^{-6} \mathrm{~m}^{2} / \mathrm{s}$ in the longitudinal, turn-to-turn and layer-to-layer directions respectively, so that over the test current transients, the thermal diffusion distance is on the order of $10-20 \%$ of the coil extent in all 3 directions. Thus an adiabatic model, as in fact is used here, is expected to somewhat over-estimate temperature excursions. Fig. 5 compares the model predictions of adiabatic temperature rise with the measurements. We immediately comment that the level of agreement is fortuitously high.

At low test current levels, the resistive heating component is found to be much less than the experimental results; however the model estimates of hysteretic heating at the measurement point are sufficient to account for the

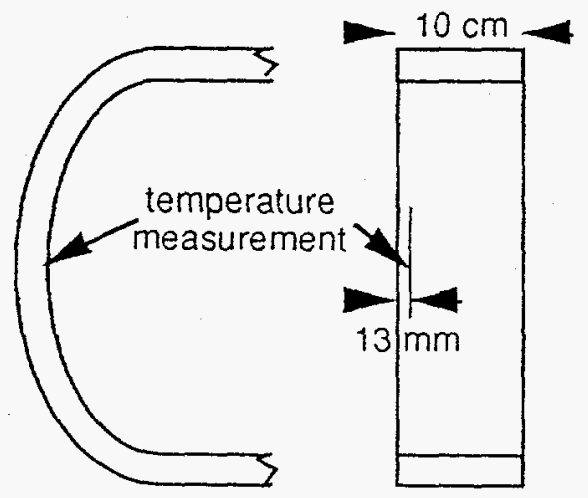

Fig. 4. Temperature measurement point.
TABLE II

CURRENT TRANSIENT TEST RESULTS

\begin{tabular}{lllll}
\hline$I_{\text {peak }}$ & Lise & thold $_{\text {holl }}$ & trall & $\Delta T(K)$ \\
\hline 30 & 2.2 & 4 & 9 & 0.063 \\
42 & 2.6 & 0 & 10 & 0.107 \\
43.1 & 1.4 & 0 & 11 & 0.109 \\
46 & 1.5 & 0 & 10.5 & 0.137 \\
47.2 & 2.9 & 0 & 11 & 0.172 \\
43.6 & 2.8 & 3.5 & 11 & 0.257 \\
57 & 1.0 & 0 & 12 & 0.292 \\
61.7 & 0.9 & 0 & 12 & 0.421
\end{tabular}

total measured heating. At higher current levels, the " $\mathrm{dc}$ " loss dominates the total heating, but the hysteretic loss estimated by the model still continues to be significant.

\section{PREDICTED FAULT TRANSIENT BEHAVIOR}

Coil heating was computed according to the model for 2 simplified superconducting field coil transients illustrated in Fig. 6, based on a $25 \mathrm{~A}$ rated current. The current excursion is representative of 6-cycle generator 3-phase fault with a $25 \%$ combined subtransient and fault reactance. In the first case the field excursion $(0.17-0.67$ $0.17 \mathrm{~T}$ ) for an aircore magnetic circuit was used, so that the results model the coil behavior under self-field in the present test rig. A 3.0-6.0-3.0 T local field excursion was used in the second case to correspond to a higher-MMF field coil operating in a generator.

The results in Table III show that the hysteretic loss is the dominant term in these transients. The $\mathrm{dB} / \mathrm{dt}$ is high enough to cause significant eddy current heating, while the loss due to dc current characteristic is a minor actor because of the short duration of the event. It is clear that the transient capability of the coil in the test rig is much higher than the first transient, because of the relatively low magnetic field excursion and the high coil composite heat capacity. In the order-of-magnitude higher field excursion

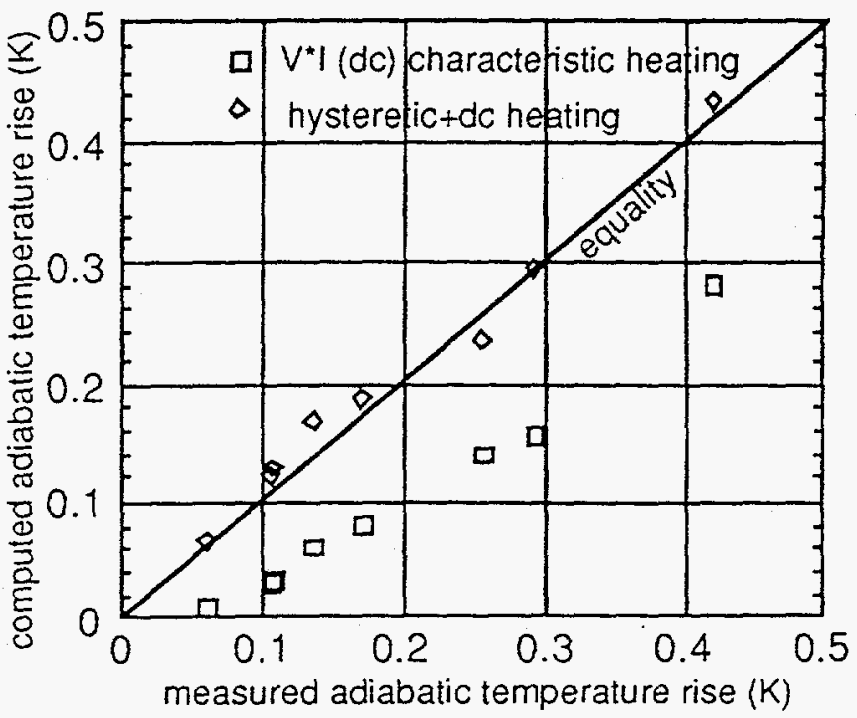

Fig. 5. Comparison of measured with computed transient heating. 


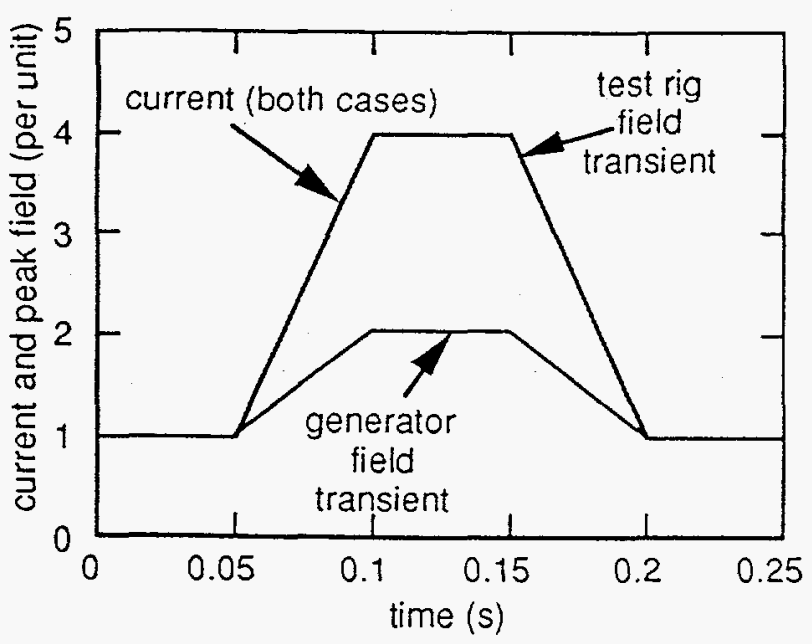

Fig. 6. Simplified field coil fault transicnt.

of the generator application, the ac losses produce a $13 \mathrm{~K}$ temperature rise, showing that we are approaching the conductor capability limit.

\section{DISCUSSION AND CONCLUSION}

These results show that copper-laminated and paper-insulated multifilamentary $\mathrm{Bi}-2223$ conductor can be utilized in coils consisting of many kilometers of conductor. The electrical performance of such a coil can be successfully analyzed on the basis of measurements of individual lengths. The dc performance can be analyzed (in order of increasing current levels) in terms of a residual resistivity regime $(1.0<n<1.5)$, a higher $n$-value regime $(5<n<10)$ and a stabilizer-current-sharing regime. Other workers [2], [3] have associated the residual resistivity level with the amount of conductor processing and handling damage. The residual resistivity level seen here is not a problem for $20 \mathrm{~K}$

\section{TABLE III}

\section{COIL TRANSEENT TEMPERATURE EXCURSION}

\begin{tabular}{|c|c|c|c|c|}
\hline $\begin{array}{l}\text { Field Excursion } \\
\text { (T) }\end{array}$ & $\mathrm{dc}$ & $\begin{array}{l}\text { Local Ten } \\
\text { hysteresis }\end{array}$ & $\begin{array}{l}\text { mperature Excu } \\
\text { eddy-current }\end{array}$ & (K) \\
\hline $\begin{array}{l}0.17-0.67-0.17 \\
3.0-6.0-3.0\end{array}$ & $\begin{array}{l}0.12 \\
0.3\end{array}$ & $\begin{array}{l}0.36 \\
9.1\end{array}$ & $\begin{array}{l}0.11 \\
4.0\end{array}$ & $\begin{array}{l}0.6 \\
13\end{array}$ \\
\hline
\end{tabular}

generator field coil operation because the resulting heat load is not excessive in view of other heat load components, and because persistent-mode operation is not required. However these results indicate that residual resistivity will be a critical issue in persistent-mode applications such as MRI.

Hysteretic ac losses should be computed on the basis of magnetization-based critical current measurements, rather than lower transport current based measurements. The Bean critical state model is adequate for predicting these losses. The capability of $20 \mathrm{~K}$ (and higher temperature) HTS coils to deal with current overdrive transients of many times $I_{c}$ is remarkable. Much higher transient heating can be tolerated than for the previous generation of LTS generator designs due to the much higher heat capacity at 20K. Therefore a lower level of EM shielding of the field coil is necessary.

The test results and analysis presented here give a high level of confidence that performance of a full-scale generator field coil can be predicted from conductor length dc test results. Such predictions suggest that the Bi-2223 test coil will perform well in a superconducting generator under 3-phase faults.

\section{ACKNOWLEDGMENTS}

We acknowledge fruitful discussions with P. Haldar.

\section{REFERENCES}

[1] K. G. Herd, L. Salasoo, E. T. Laskaris, R.A. Ranze, C.G. King, P. Haldar and J.G. Hoehn, "Development and fabrication of a Bi-2223 racetrack coil for generator applications", Paper LI-6 this conference, 1996.

[2] Y. Fukumoto, Q. Li, Y.L. Wang, M. Suenaga and P. Haldar, "Very low level residual resistivity in silver-sheathed $(\mathrm{Bi}, \mathrm{Pb})_{2} \mathrm{Sr}_{2} \mathrm{Ca}_{2} \mathrm{Cu}_{3} \mathrm{O}_{8}$ tapes", Appl. Phys. Lett. vol. 66, no. 14. pp. 1827-1829, 3 April 1995.

[3] Q. Li, H.J. Wiesman, M. Suenaga, L. Motowidlo and P. Haldar, "Vortex phase diagram and $\mathrm{J}_{c}$ limiting factor in high $\mathrm{T}_{\mathrm{c}} \mathrm{Bi}_{2} \mathrm{Sr}_{2} \mathrm{Ca}_{2} \mathrm{Cu}_{3} \mathrm{O}_{10} / \mathrm{Ag}$ superconducting tapes", Appl. Phys. Lett. vol. 66, no. 5, pp. 637-639, 30 January 1995.

[4] J.E. Tkaczyk, R.H. Arendt, M.F. Garbauskas, H.R. Hart Jr, K.W. Lay and F.E. Luborsky, "Critical-state scaling and weak links in $\mathrm{Ag}$-sheathed $\mathrm{Bi}_{2} \mathrm{Sr}_{2} \mathrm{Ca}_{2} \mathrm{Cu}_{3} \mathrm{O}_{2}$ ". Phys. Rev. $B$ vol. 45. no. 21, pp. 12506-12511, 1 June 1992.

\title{
DISCLAIMER
}

\begin{abstract}
This report was prepared as an account of work sponsored by an agency of the United States Government. Neither the United States Government nor any agency thereof, nor any of their employees, makes any warranty, express or implied, or assumes any legal liability or responsibility for the accuracy, completeness, or usefulness of any information, apparatus, product, or process disclosed, or represents that its use would not infringe privately owned rights. Reference herein to any specific commercial product, process, or service by trade name, trademark, manufacturer, or otherwise does not necessarily constitute or imply its endorsement, recommendation, or favoring by the United States Government or any agency thereof. The views and opinions of authors expressed herein do not necessarily state or reflect those of the United States Government or any agency thereof.
\end{abstract}




\section{DISCLAMMIER}

Portions of this document may be illegible in electronic image products. Images are produced from the best available original document. 